\title{
Not the same thing: metastatic PTCs have a different background than ATCs
}

\author{
Dario de Biase', Federica Torricelli², Moira Ragazzi ${ }^{3}$, Benedetta Donati², Elisabetta Kuhn ${ }^{3}$, Michela Visani ${ }^{4}$, \\ Giorgia Acquaviva ${ }^{4}$, Annalisa Pession', , Giovanni Tallini ${ }^{4}$, Simonetta Piana ${ }^{3}$ and Alessia Ciarrocchi ${ }^{2}$ \\ ${ }^{1}$ Department of Pharmacy and Biotechnology (Dipartimento di Farmacia e Biotecnologie) - Molecular Diagnostic Unit, Azienda USL di Bologna, \\ University of Bologna, Bologna, Italy \\ ${ }^{2}$ Laboratory of Translational Research, Azienda Unità Sanitaria Locale AUSL-IRCCS, Reggio Emilia, Italy \\ ${ }^{3}$ Pathology Unit, Azienda Unità Sanitaria Locale AUSL-IRCCS, Reggio Emilia, Italy \\ ${ }^{4}$ Department of Medicine (Dipartimento di Medicina Specialistica, Diagnostica e Sperimentale) - Molecular Diagnostic Unit, Azienda USL di Bologna, \\ University of Bologna School of Medicine, Bologna, Italy
}

Correspondence should be addressed to A Ciarrocchi or D de Biase: alessia.ciarrocchi@ausl.re.it or dario.debiase@unibo.it

\begin{abstract}
Anaplastic thyroid cancer (ATC) is a rare but highly aggressive form of thyroid cancer. By contrast, differentiated papillary thyroid cancer (PTC) only rarely behave aggressively and develop distant metastasis. Whether distantly metastatic PTC (DM-PTC) and ATC share a common genetic background is still to be defined. We used next-generation sequencing (NGS) to explore the genetic background of a cohort of ATC and DM-PTC and a group of well-differentiated PTCs that did not developed distant metastasis as control (ctrl-PTC). A panel of 128 amplicons within 21 thyroid cancer-related genes was analyzed in a set of 151 thyroid cancer samples including 66 ATCs and DM-PTCs. We showed that the ATC/DM-PTC group had an overall mutational load higher than ctrl-PTCs and that ATCs and DM-PTCs are characterized by a different genetic background, with the exception of mutations in the TERT promoter that were overrepresented in both ATCs (61.1\%) and DM-PTCs (48.2\%) vs non-aggressive ctrl-PTCs (7.6\%). In ATCs, TERT promoter mutations were frequently associated with TP53 mutations, while in the DM-PTCs no significant co-occurrence was observed. No significant association of MED12 mutations with aggressiveness of thyroid cancer was observed in our analysis. Finally, correlation analysis showed that increasing number of mutations negatively impact on patient overall survival also within the ATC and DM-PTC group. In conclusions, overall our analysis further highlights the relevance of TERT promoter mutations in driving aggressiveness and provides new pieces of information in the definition of aggressiveness evolution of thyroid cancer lesions.
\end{abstract}

\section{Key Words}

- highly aggressive thyroid cancer

- genetic profile

- TERT promoter mutations

- anaplastic thyroid cancer

- papillary thyroid cancer

- MED12 mutations

\section{Introduction}

Thyroid tumors are the most common malignancies of the endocrine system and their incidence has constantly increased over the past years (1). Based on histological and cytological features, thyrocyte-derived tumors are classified into three categories: well-differentiated, poorly differentiated and anaplastic. Aggressiveness and lethality of the tumors decrease with grade of cell differentiation (2).
Anaplastic thyroid carcinoma (ATC) is a rare but highly aggressive form of thyroid cancer (3). It represents 1-2\% of clinically recognized thyroid malignancies but it accounts for more than half of the deaths for thyroid cancer. Fiveyear survival rate for ATC patients is estimated below $1 \%$ and about $50 \%$ of ATC patients die within 1 year from diagnosis. Well-differentiated papillary thyroid

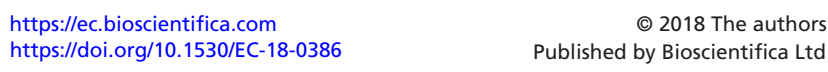

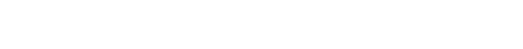

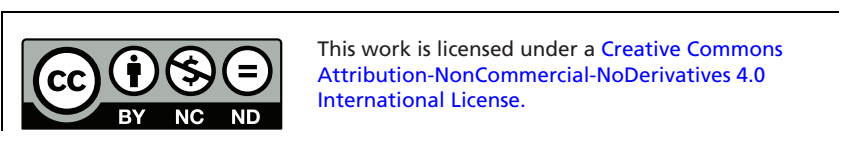


cancers (PTCs) are considered indolent tumors, with slow rate of growth, low metastatic potential and excellent prognosis (10-year patient survival rate up to 95\%) $(4,5)$. Nevertheless, a small but significant percentage of differentiated PTCs behave aggressively progressing to a diffuse metastatic spreading disease and leading in 1-2\% of total cases to patient's death (6).

The relationship between differentiated and undifferentiated thyroid carcinoma has long been a point of interest $(7,8,9)$. Recently the genomic landscapes of both PTCs (10) and ATCs $(11,12,13)$ have been described. While PTCs are characterized by a high genomic stability and a very low mutation density ( 0.41 non-synonymous mutations per $\mathrm{Mb}$, on average), ATCs are characterized by a high degree of genomic abnormalities that underscore their virulence and elevated mortality rate. Still few information on the genetic alterations associated with metastatic PTCs are currently available. However, recent evidence indicates that aggressiveness and lethality of well-differentiated PTCs rely on a precise pattern of genetic aberrations suggesting that genetic diversity discriminate these highly aggressive lesions from the vast majority of indolent PTCs (14). Furthermore, a recent report identifies mutations in MED12 and in TERT promoter as shared genetic features between ATC and fatal non-ATC thyroid lesions, hypothesizing a common genetic background behind the common clinical aggressiveness of these different types of thyroid cancer (15).

Here, we used NGS approach to explore the genetic features of a large cohort of 48 highly aggressive thyroid cancers composed of ATCs and widely metastatic welldifferentiated PTCs in order to define common or peculiar genetic features associated with these highly aggressive forms of thyroid cancer.

\section{Materials and methods}

\section{Case selection and DNA extraction}

A total of 151 thyroid cancer samples were retrieved from the thyroid archive of Anatomic Pathology of 'Arcispedale Santa Maria Nuova' (Reggio Emilia, Italy). All DM-PTC and ATC diagnosed in our institution since 1975 were included in this set $(n=66)$. As control, we selected welldifferentiated PTC $(N=85)$ that did not develop distant metastasis with a minimum follow-up of 8 years. Part of this patient cohort has been the object of our previous study (14). All analyses were performed from formalin-fixed and paraffin-embedded (FFPE) specimens. Only primary lesions were analyzed. In order to assess the molecular status of the genes analyzed, after careful review of sections by two pathologists (M R, S P), DNA was extracted from FFPE material scraped under microscope guidance from ten $5-\mu \mathrm{m}$ thick sections, using the FFPE Plus LEV DNA Purification Kit (Promega) and the Maxwell 16 instrument (Promega). DNA quality and quantity were assessed using Nanodrop and Qubit (Thermo Fisher Scientific) (14). The study was approved by Ethical Committee of the Reggio Emilia IRCCS-Arcispedale Santa Maria Nuova. Consent has been obtained from all leaving patients, still in follow-up at our institution, after full explanation of the purpose and nature of the study. For all deceased patients permit were obtained from the Privacy Authority. All information regarding the human material was managed using anonymous numerical codes. All samples were handled in compliance with the Helsinki Declaration (http://www.wma.net/en/30publications/10policies/b3/).

\section{Next-generation sequencing analysis}

To define the genetic profile associated with highly aggressive forms of thyroid cancer, we used NGS approach to sequence a panel of 128 amplicons (dual strand, for a total of 256 amplicons) within 21 established oncogenes or oncosuppressors. The samples were analyzed using a customized panel of genomic regions and sequenced by MiSeq Sequencer (Illumina Inc, San Diego, CA, USA), according to manufacturers' instruction. At least $20 \mathrm{ng}$ of DNA were used for amplicon-library preparation. The custom panel included the following targeted gene regions: BRAF (exon 15), KRAS (exons 2, 3, 4), NRAS (exons 2, 3, 4), HRAS (exons 2, 3), EGFR (exons 12, 18, 19, 20, 21), CTNNB1 (exon 3), EIF1AX (exons 1, 2), GNAS (exons 8, 9), H3F3A (exon 1), IDH1 (exon 4), IDH2 (exon 4), MED12 (exon 2), c-Kit (exons 8, 9, 11, 13, 17), MET (exon 2, 14), $c$-Myc (exons 1, 2, 3), PDGR $\alpha$ (exons 12, 14, 18), PIK3CA (exons 10, 21), PTEN (exon 5), RET (exons 5, 8, 10, 11, 13, 15, 16), SMAD4 (exons 6, 9, 10, 11, 12), TP53 (exons 4, 5, $6,7,8,9)$, TERT (promoter region. The sequences obtained were analyzed using VariantStudio Software (Illumina Inc, San Diego, CA, USA) and the Integrative Genomics Viewer 2.3 (IGV) tool (http://software.broadinstitute.org/ software/igv/). Only mutations that were present in at least $5 \%$ of the total number of reads analyzed and observed in both strands were considered for mutational calls.

\section{Statistical analysis}

Categorical variables were compared using the Chi-square test or Fisher's exact test. Continuous variables were 
compared using the $t$-Student test. Statistical survival comparisons were determined by log-rank (MantelCox) test. A $P$ value $<0.05$ was considered as statistically significant. Statistical analyses were performed using GraphPad Prism 6.01 (GraphPad Software).

\section{Results}

\section{Patients and tumor features}

Of 151 thyroid samples analyzed, 66 were highly aggressive thyroid cancers (HA-TCs). In particular, 18 were ATCs while 48 were well-differentiated PTCs that developed distant metastasis (DM-PTC). The remaining 85 tumors in this set were well-differentiated PTCs that did not develop distant metastasis based on a minimum follow-up of 8 years (ctrl-PTCs). Of these, 37 tumors were confined to the thyroid (NO) and 48 presented lymph nodal metastasis (N1).

Of 151 patients, 47 were males and 104 females, with age ranged from 16 to 84 years (mean: 58.7 years). Age was significantly higher in the ATC subgroup (Table 1 ). Lung was the most frequent metastatic site (54.1\%, data not shown). Of 151 cases, 88 were diagnosed as
'classic-PTC' (C-PTC, 58.3\%), 25 as 'Tall-cell Variant-PTC' (TCV-PTC, 16.6\%), 17 as 'Follicular Variant-PTC' (FV-PTC, 11.3\%), 3 as 'Solid-Trabecular PTC' (ST-PTC, 2.0\%) and 18 as 'Anaplastic Thyroid Carcinomas' (ATC, 11.9\%) (Table 1). The mean overall survival ranged from $27.9 \mathrm{~ms}$ (ATC group) to $157.2 \mathrm{~ms}$ (N0 group) (Table 1). Within the subgroup of aggressive tumors, 39 of 66 (59.1\%) died because of the disease while 15 (17.6\%) patients displayed tumor persistence. By contrast, only five out of 85 (5.9\%) non-metastatic tumors (N0+N1) showed evidence of persistent disease (Table 1 and Supplementary Tables 1, 2, 3 and 4 , see section on supplementary data given at the end of this article).

\section{Genetic features HA-TCs vs ctrl-PTCs}

A total of 113 samples (47 HA-TCs and 66 ctrl-PTCs) yielded a DNA amount and quality suitable for this analysis. Clinicopathological features of these 113 specimens are summarized in Supplementary Tables 1, 2, 3 and 4. A total of 133 somatic mutations were identified (Fig. 1A and $\mathrm{B}$ and Supplementary Table 5). Frequency of mutations was significantly higher in the HA-TC group as compared with the non-aggressive lesions $(P=0.0307)$ (Fig. 2A).

Table 1 Clinicopathological features of cases analyzed by NGS.

\begin{tabular}{|c|c|c|c|c|c|c|}
\hline Group & Num of cases & Age (mean) (years) & Sex & Histology & Fu (range) & FU (event) \\
\hline DM-PTC & 29 & 53.0 & $\begin{array}{c}11 \mathrm{M} \\
18 \mathrm{~F}\end{array}$ & $\begin{array}{l}17 \text { C-PTC } \\
8 \text { TCV-PTC } \\
3 \text { FV-PTC } \\
1 \text { ST-PTC }\end{array}$ & $101.7 \mathrm{~ms}(24-234)$ & $\begin{array}{l}15 \text { DOD } \\
11 \text { AWD } \\
2 \text { NED } \\
1 \text { NA }\end{array}$ \\
\hline ATC & 18 & 70.6 & $\begin{array}{l}7 \mathrm{M} \\
11 \mathrm{~F}\end{array}$ & 18 ATC & $27.9 \mathrm{~ms}(1-195)$ & $\begin{array}{l}11 \text { DOD } \\
1 \text { AWD } \\
2 \text { DOC } \\
4 \text { NA }\end{array}$ \\
\hline HA-TC & 47 & 59.7 & $\begin{array}{l}18 \mathrm{M} \\
29 \mathrm{~F}\end{array}$ & $\begin{array}{l}17 \text { C-PTC } \\
8 \text { TCV-PTC } \\
3 \text { FV-PTC } \\
1 \text { ST-PTC } \\
18 \text { ATC }\end{array}$ & $69.3 \mathrm{~ms}(1-234)$ & $\begin{array}{l}26 \text { DOD } \\
12 \text { AWD } \\
2 \text { DOC } \\
2 \text { NED } \\
5 \text { NA }\end{array}$ \\
\hline No & 32 & 54.9 & $\begin{array}{l}6 \mathrm{M} \\
26 \mathrm{~F}\end{array}$ & $\begin{array}{l}25 \text { C-PTC } \\
2 \text { TCV-PTC } \\
4 \text { FV-PTC } \\
1 \text { ST-PTC }\end{array}$ & $136.3 \mathrm{~ms}(77-216)$ & $\begin{array}{l}30 \text { NED } \\
2 \text { NA }\end{array}$ \\
\hline N1 & 34 & 49.1 & $\begin{array}{l}13 \mathrm{M} \\
21 \mathrm{~F}\end{array}$ & $\begin{array}{l}24 \text { C-PTC } \\
6 \text { TCV-PTC } \\
4 \text { FV-PTC }\end{array}$ & $157.2 \mathrm{~ms}(85-373)$ & $\begin{array}{l}5 \text { AWD } \\
25 \text { NED } \\
4 \text { DOC }\end{array}$ \\
\hline ctrl-PTCs & 66 & & $\begin{array}{c}19 \mathrm{M} \\
47 \mathrm{~F}\end{array}$ & $\begin{array}{l}49 \text { C-PTC } \\
8 \text { TCV-PTC } \\
8 \text { FV-PTC } \\
1 \text { ST-PTC }\end{array}$ & $142.1 \mathrm{~ms}(77-373)$ & $\begin{array}{l}5 \text { AWD } \\
55 \text { NED } \\
4 \text { DOC } \\
2 \text { NA }\end{array}$ \\
\hline
\end{tabular}

ATC, anaplastic thyroid carcinoma; AWD, alive with disease; C-PTC, classic papillary thyroid carcinoma; ctrl-PTCs, control group (N0+N1); DM-PTC, distantly metastatic PTC; DOC, dead of other cause; DOD, dead of disease; F, female; FU, follow-up; FV, follicular variant; HA-TC, highly aggressive thyroid carcinoma (DM-PTC + ATC); M, male; ms, months; N0, no lymph nodal involvement at presentation; N1, lymph nodal involvement at presentation; NA, not available; NED, not evidence of disease; ST, solid trabecular; TCV, tall-cell variant. 
Indeed, 66 mutations were detected in the HA-TC subgroup (1.40 mutations/sample) while 67 were detected in the non-aggressive lesions (0.98 mutations/sample). Furthermore, $44.6 \%$ of HA-TC samples displayed two or more mutations vs $27.3 \%$ of ctrl-PTC cases, confirming that aggressive phenotype is associated with increased genetic alterations (Fig. 2B). No significant differences in the allele mutation frequency were observed either in the HA-TCs vs ctrl-PTCs comparison or between ATCs and DM-PTCs (Fig. 2C and D).

Most of the mutations were transitions (56.8\%), followed by transversions (37.9\%), indels (3.0\%) and stop mutations (2.3\%) (Fig. 2E). The most recurrent mutation was the BRAF p.V600E observed in 39 cases (14 N1, 14 N0, 10 DM-PTC and 1 ATC). MET p.N375S and p.E168D and PI3KCA p.R524K mutations were each observed in three cases.

Mutations in the TERT promoter (26.5\%) and in the $B R A F$ gene $(37.1 \%)$ showed the highest frequency within the entire set of samples analyzed (Fig. 1A and B). However, these two mutations showed a complementary trend with TERT promoter mutations massively associated with the
HA-TC subgroup (53.2\% in HA-TCs vs $7.6 \%$ in ctrl-PTCs, $P<0.0001)$ and the $B R A F$ mutations most frequently found in the non-aggressive PTC subgroup (25.5\% in HA-TCs vs $45.5 \%$ in ctrl-PTCs, $P=0.047$ ) (Fig. $2 \mathrm{~F}$ and Table 2 ).

GNAS mutations were found almost exclusively in HA-TCs $(8.5 \%)$ with only one the ctrl-PTC cases $(1.5 \%)$ displayed alteration in this gene. Noticeably, in the highly aggressive group, GNAS mutations were associated with TERT promoter mutations in each sample except one (Fig. 1A and B).

No mutations in HRAS and KRAS were detected in our set, while NRAS mutations were detected only in the highly aggressive group (4.3\%) and restricted to the ATC subgroup were these mutations were mutually exclusive with the BRAF mutations (Fig. 1A and B). These frequencies are lower than previously reported $(15,16)$. $R A S$ mutations have been associated primarily to follicular thyroid carcinoma (FTC). The low frequency of FTC variants in our cohort likely accounts for this discrepancy.

Recently, mutations in MED12 were described as preferentially associated with non-ATC fatal forms of thyroid cancer (15). In our set, 13 out of 113 thyroid
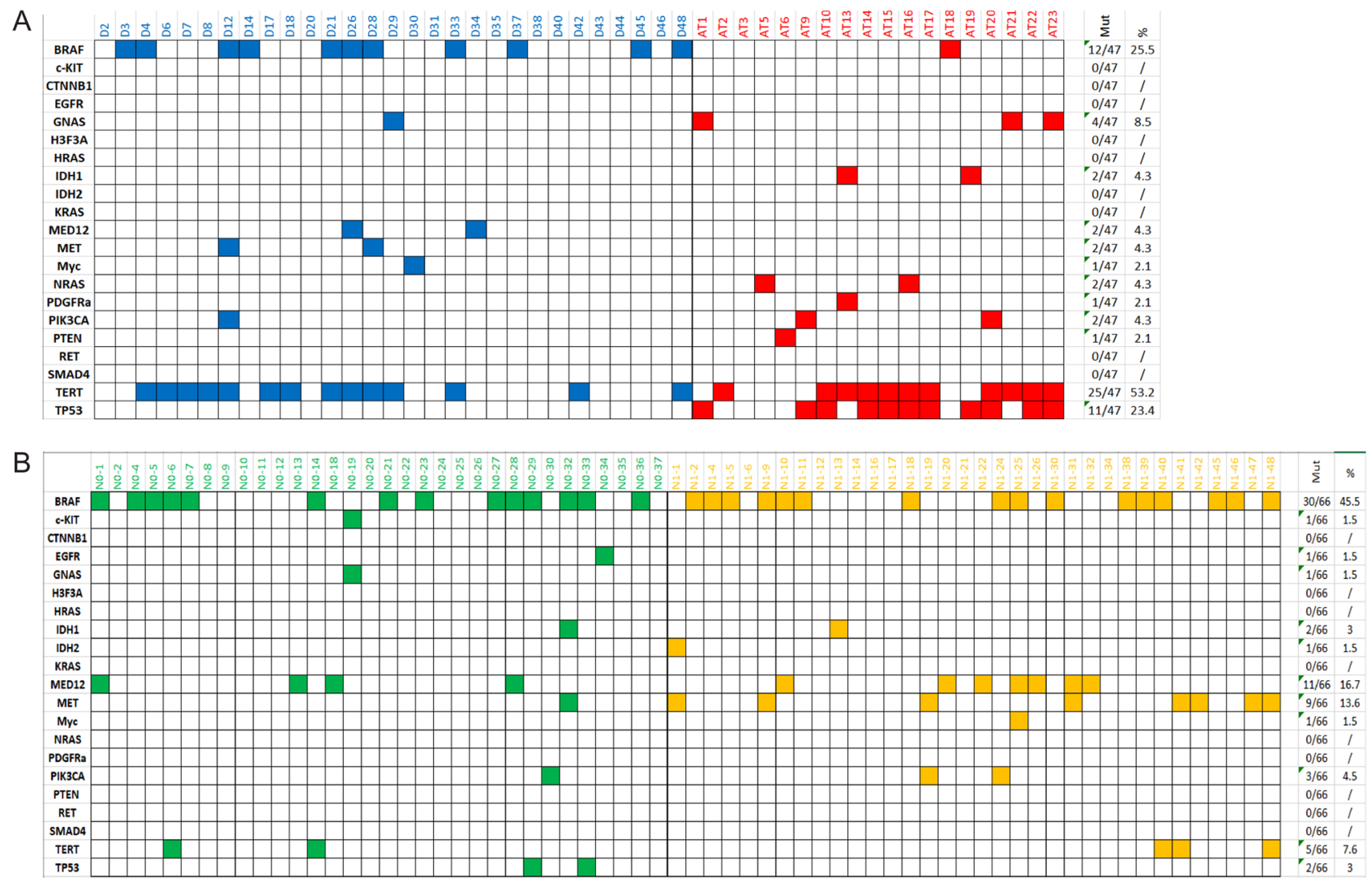

\section{Figure 1}

Summary of genetic mutations found in 113 samples analyzed. (A) Represents HA-TCs while (B) represents ctrl-PTCs. Different colors were used for the different tumor subtypes: blue for DM-PTC, red for ATC, green for N0 and yellow for N1.

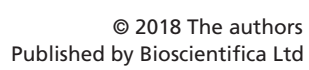

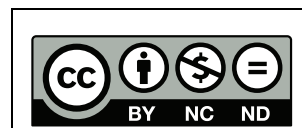

This work is licensed under a Creative Commons Attribution-NonCommercial-NoDerivatives 4.0 International License. 
B
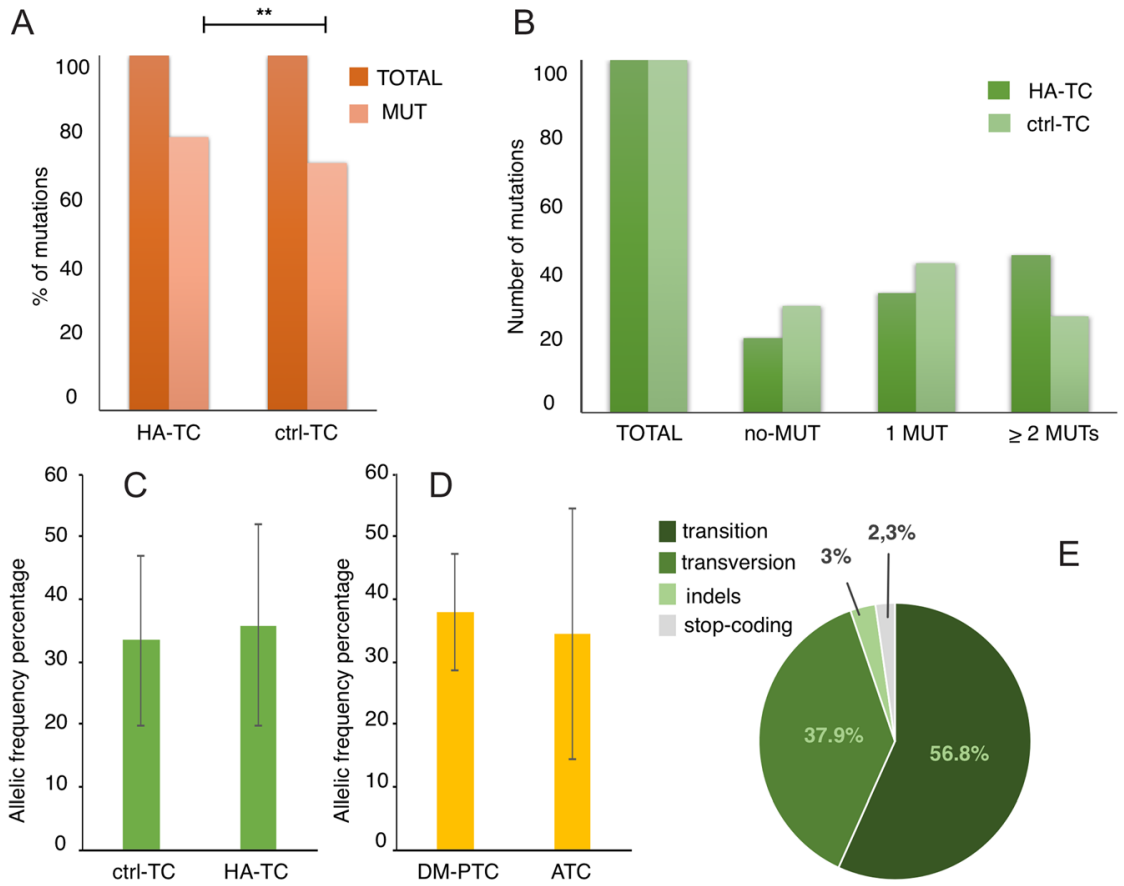

E

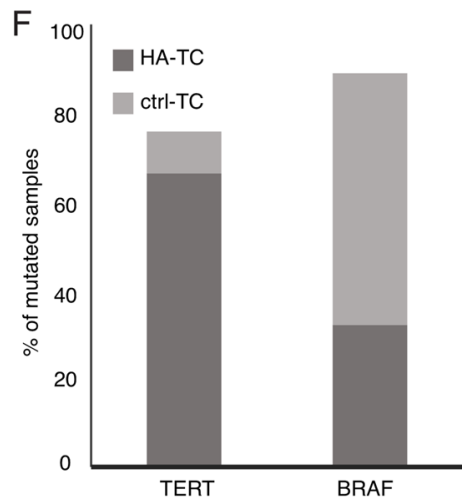

G
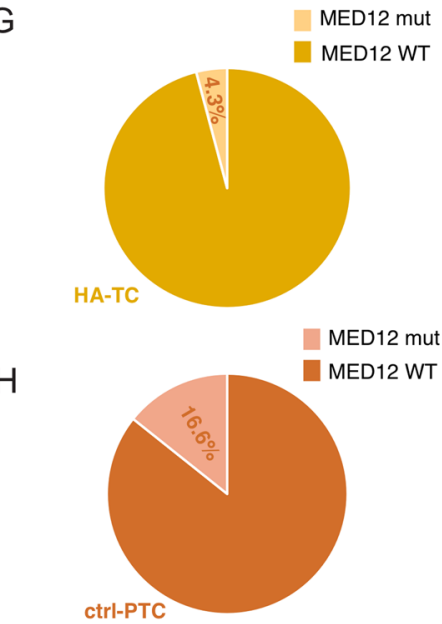

Figure 2

Percentage of mutated samples for each group (A). Distribution of samples according to the number of mutations displayed (B). Allelic frequency percentage in ctrl-TC and in HA-TC groups (C) and in DM-PTC and ATC groups (D). Type of mutation according to the type of nucleotide substitution (E). Schematic representation of TERT and BRAF mutations distribution in HA-TC and ctrl-PTC samples (F). Occurrence of MED12 mutations in HA-TC (G) and ctrl-PTC samples (H). cancers (11.5\%) were positive for MED12 mutations. Frequency of mutated allele ranged from 15 to 52\% (mean $26.8 \%$ ). According to PolyPhen prediction, eight MED12 mutations were 'probably damaging' (PolyPhen score ranging from 0.616 to 0.999 ) and three were 'benign' (PolyPhen score ranging from 0.02 to 0.254 ). Differently from what previously reported, we could not appreciate association of MED12 with tumor aggressiveness. Indeed, only two out of 47 HA-TC samples (4.3\%) carried MED12 mutations, while mutations in this gene characterize $16.7 \%$ of the ctrl-PTC group (11/66) (Fig. 2G and H). This rate of mutation was similar to the one previously reported for MED12 mutations in aggressive non-ATCs thyroid cancer (15). Of the 18 ATC samples analyzed none

$\begin{array}{lr}\text { https://ec.bioscientifica.com } & \text { () } 2018 \text { The authors } \\ \text { https://doi.org/10.1530/EC-18-0386 } & \text { Published by Bioscientifica Ltd }\end{array}$

were positive for this mutation, while $6.8 \%$ of DM-PTCs were MED12 mutated. No significant differences were observed in the frequency of MED12 mutations between N1-PTCs and N0-PTCs within the non-aggressive thyroid cancer group $\left(\mathrm{Chi}^{2} \mathrm{P}=0.378\right)$.

\section{ATCs and DM-PTCs are genetically different, with} the exception of TERT promoter mutations

To explore the possibility that a common genetic signature could underline aggressive behavior of undifferentiated and well-differentiated PTCs, we compared the mutational profile of ATCs and DM-PTCs within the HA-TC group. As previously reported, ATCs presented a significantly higher

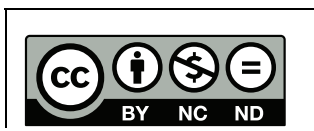

This work is licensed under a Creative Commons Attribution-NonCommercial-NoDerivatives 4.0 International License. 
Table 2 Contingency tables of relevant gene mutations.

\begin{tabular}{|c|c|c|c|c|c|c|}
\hline & DM-PTC (29) & ATC (18) & & DM-PTC + ATC (47) & $\mathbf{N 0}+\mathbf{N} 1(66)$ & \\
\hline & $\%$ & $\%$ & & $\%$ & $\%$ & \\
\hline$B R A F$ & & & 0.017 & & & 0.047 \\
\hline$w t$ & $62.01(18)$ & $94.4(17)$ & & $74.5(35)$ & $54.5(36)$ & \\
\hline mut & $37.9(11)$ & $5.6(1)$ & & $25.5(12)$ & $45.5(30)$ & \\
\hline GNAS & & & 0.283 & & & 0.158 \\
\hline$w t$ & $96.5(28)$ & $83.3(15)$ & & $91.5(43)$ & $98.5(65)$ & \\
\hline mut & $3.5(1)$ & $16.6(3)$ & & $8.5(4)$ & $1.5(1)$ & \\
\hline MED12 & & & 0.517 & & & 0.069 \\
\hline$w t$ & $93.1(27)$ & $100(18)$ & & $95.7(45)$ & $83.3(55)$ & \\
\hline mut & $6.9(2)$ & $0(0)$ & & $4.3(2)$ & $16.7(11)$ & \\
\hline MET & & & 0.517 & & & 0.118 \\
\hline$w t$ & $93.1(27)$ & $100(18)$ & & $95.7(45)$ & $86.4(57)$ & \\
\hline mut & $6.9(2)$ & $0(0)$ & & $4.3(2)$ & $13.6(9)$ & \\
\hline TERT & & & 0.549 & & & $<0.0001$ \\
\hline$w t$ & $51.7(15)$ & $38.9(7)$ & & $46.8(22)$ & $92.4(61)$ & \\
\hline TP53 & & & $<0.0001$ & & & 0.001 \\
\hline$w t$ & $100(29)$ & $38.9(7)$ & & $76.6(36)$ & $97(64)$ & \\
\hline mut & $0(0)$ & $61.1(11)$ & & $23.4(11)$ & $3(2)$ & \\
\hline
\end{tabular}

Significance of differences on mutation frequency for the indicated genes was evaluated by Fisher exact test.

mutational load than DM-PTCs $(P=0.0099)$ (Fig. 3A) (14). Thirty-two mutations were detected in the DM-PTC group (1.1 mutations/sample) while 34 were detected in the ATC group (1.89 mutations/sample). The overall mutation frequency in the DM-PTC groups was not significantly different from the one observed in the non-metastatic PTCs (0.98 mutations/sample), in accordance with our previous reports (14). Mutations in the TERT promoter were the most frequent alterations detected in both groups. TP53 mutations were exclusive of ATCs while BRAF mutations showed a massive predominance in the DM-PTCs group with only 1 ATC displaying alterations in this gene (Fig. 3B and Table 2). Of the 24 DM-PTCs mutated either in BRAF or TERT promoter only five showed concomitant occurrence of these alterations, while the only $B R A F$ mutated ATC did not displayed alterations in the TERT promoter sequence (Fig. 3C and D). Instead, we observed a significant co-occurrence between p53 and TERT promoter mutations in the ATC group with 57\% (8/14) of mutated samples showing both alterations (Fig. 3D). Taking into consideration the other genes included in the panel, GNAS was more frequently mutated in ATCs (16.6\%) than in DM-PTCs (3.4\%), while MED12 and MET resulted altered exclusively in the DM-PTC group $(6.8 \%)$ without reaching significance (Fig. 3B and Table 2). Overall, these data confirm that mutations in the TERT promoter are the most reliable marker of aggressiveness being strongly associated with both undifferentiated and well-differentiated highly aggressive forms of thyroid cancer. Furthermore, these data seem to indicate that

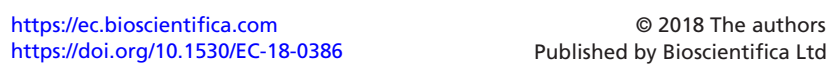

DM-PTC and ATC are genetically different and likely evolve through different molecular mechanisms.

\section{Mutational load negatively affects survival of thyroid cancer patient}

It is established that high degree of genomic instability negatively affects patient outcome.

Thus, we explored the correlation between number of mutation and disease-specific survival (DSS) probability in our set of samples. A higher number of mutations was significantly associated with decreased DSS probability within the entire set of 113 samples analyzed (Fig. 4A). This was expected due to the significant association observed between the number of mutations and the highly aggressive form of thyroid cancer. Next, we investigated the effect of mutational load on DSS only within the HA-TC group (Fig. 4B). Noticeably, also within the group of highly aggressive thyroid cancers, the number of mutations was inversely correlated with DSS. This indicates that mutational load impacts on patient outcome more than just contributing to the acquisition of an aggressive phenotype.

\section{Discussion}

Aggressiveness and lethality are uncommon features of thyroid cancers and are usually associated with undifferentiated or poorly differentiated states of

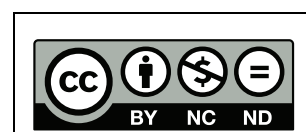

This work is licensed under a Creative Commons Attribution-NonCommercial-NoDerivatives 4.0 International License. 


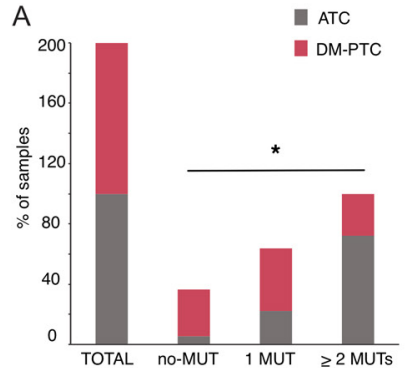

B

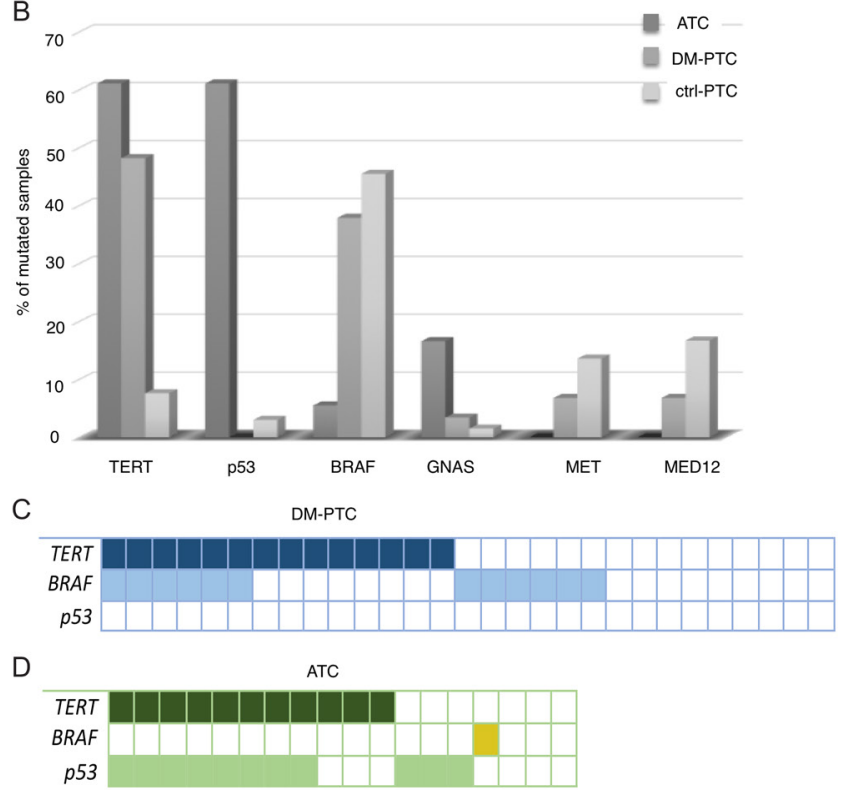

Figure 3

Differential distribution of HA-TC and ctrl-PTC samples according to the number of mutations (A). Frequency of mutated samples for each gene in HA-TC, DM-PTC and ctrl-PTC samples (B). Representation of concomitant mutations in the three most frequently altered genes (TERT, BRAF and TP53) in DM-PTC (C) and ATC (D).

tumor cells. Still, a small but significant fraction of welldifferentiated thyroid cancers develop metastasis and lead to fatal outcomes $(5,17)$. The current inability of discriminating at the time of diagnosis those rare differentiated lesions that will behave aggressively developing metastasis represents a severe limitation to a correct risk-based stratification of the patients inducing likely aggressive overtreatment where not needed. As well, the relative rarity of these lesions and the slow course of this disease make it difficult to collect sufficiently large cohorts of patients to get information on the genetic and molecular background of these lesions. In spite of the profound morphological differences an intriguing possibility is that ATCs and DM-PTCs may share common genetic backgrounds underlining the common clinical aggressiveness. In this study, we addressed this issue studying the genetic features of a large cohort of ATCs and

$\begin{array}{lr}\text { https://ec.bioscientifica.com } & \text { ( } 2018 \text { The authors } \\ \text { https://doi.org/10.1530/EC-18-0386 } & \text { Published by Bioscientifica Ltd }\end{array}$
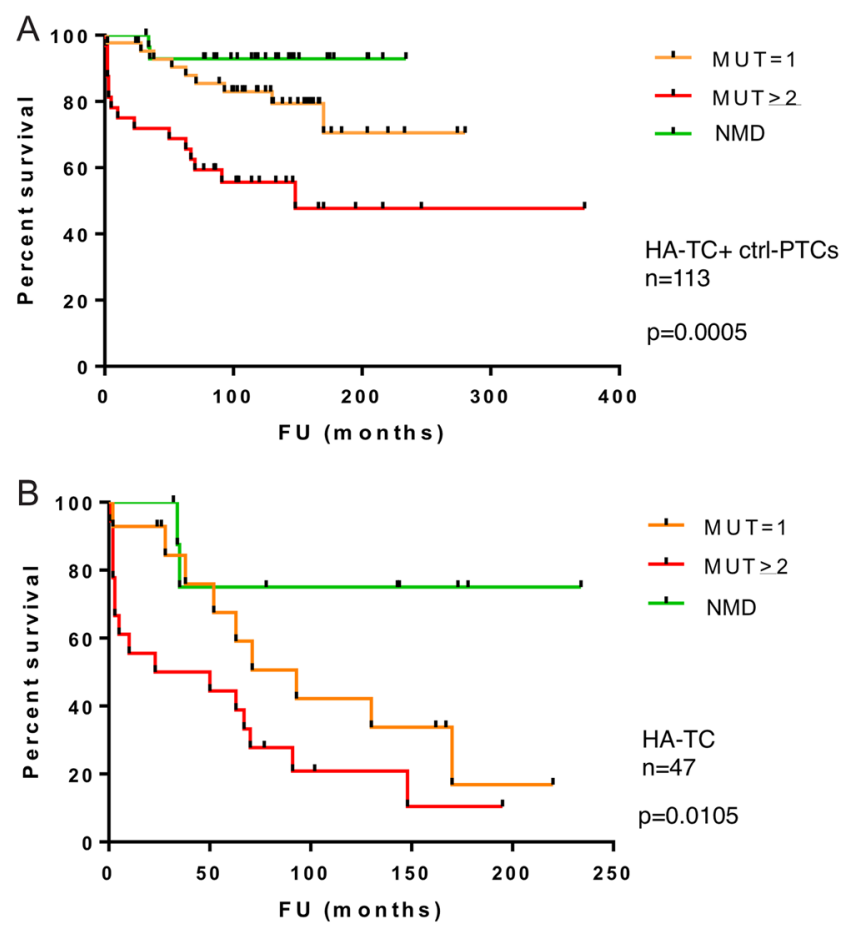

Figure 4

Kaplan-Meier plots for association number of mutations with patient survival in the overall cohort of 113 thyroid cancer analyzed $(A)$ and restricted to the HA-TC subset (B). MUT, mutations; NMD, no detected mutations.

DM-PTCs seeking for potential commonalities. Even if not conclusive our results indicate that PTCs and ATCs rely on different genetic events and that with the single exception of TERT promoter mutations the overall mutational loads and the type of mutations detected in the two groups are significantly different.

Noticeably, we confirmed our previous observation (14) that DM-PTCs in spite of their high clinical aggressiveness are characterized by a quite low mutational load, similar in extent to the one of non-metastatic PTCs (either in our cohort or in the TCGA dataset) and quite different from the high degree of mutations displayed by ATCs. Furthermore, several mutations detected within our dataset where ascribable preferentially if not exclusively to either ATC (for example mutation in TP53 and GNAS) or to DM-PTCs (among which BRAF, MET and MED12). This different mutation distribution between ATCs and PTCs is in accordance with previous reports and seems to indicate that these lesions progress through early differentiated evolution pathways $(3,10,11,15,18)$.

Our study further confirms the relevance of TERT alterations in driving aggressiveness of thyroid cancer (17, $19,20,21,22,23,24)$. In our analysis, $60 \%$ of ATCs and $48 \%$ of DM-PTCs were characterized by mutations within

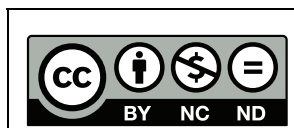

This work is licensed under a Creative Commons Attribution-NonCommercial-NoDerivatives 4.0 International License. 
the TERT promoter. These frequencies were sharply different from the $7.6 \%$ of TERT mutated samples detected in the non-aggressive non-metastatic PTCs of the control cohort and from the previously reported frequency of the TCGA data (9\%) (10). Unlimited replicative potential is a major hallmark of aggressive cancer cells (25). To fulfill the high rate of proliferation, cancer cells must protect their telomere repeats length from progressive shortening (26, 27). The telomerase complex of which TERT is a crucial and rate-limiting component is essential to counteract erosion of telomere repeats and maintaining proficient and unlimited proliferative capacity of cancer cells (27). Indeed, it has been reported that TERT promoter mutations lead to increased transcriptional activity of the promoter $(28,29,30)$ and to higher level of TERT mRNA $(31,32,33$, 34). Recently, the evidence that increased TERT expression is essential to drive metastatic behavior has been further confirmed by the evidence that duplication of the TERT locus within the chr5p is significantly associated with the development of distant metastasis in PTCs (14) and by the observation that TERT promoter mutations are also frequent in thyroid distant metastatic lesions (12).

Previous reports suggested co-occurrence and cooperation of BRAF and TERT mutations in aggressive thyroid cancers $(15,35)$. In our analysis, we could not observe a significant association of TERT and BRAF mutations, while we observed a strong correlation between TERT promoter mutations and TP53 mutations within the ATC group. Recently, Oishi and colleagues, in the attempt of identifying risk factors favoring the development of ATCs from preexisting PTC lesions observed that while TERT promoter mutations were common to both welldifferentiated and undifferentiated components of the same lesions, TP53 mutations were acquired exclusively by the ATC component (8).

This seems to indicate that TP53 mutations follow TERT alteration in the genetic evolution of ATCs. p53 is a master keeper of genomic stability and its inactivation or altered activity is often associated with genetically damaged types of cancer. It was previously reported that p53 affects also telomeres homeostasis and that telomere shortening triggers a p53-dependent cell cycle arrest (36). Thus, facing TERT altered expression (caused by TERT promoter mutations) altered p53 function may serve ATC cells to keep a proficient telomere elongation and unleashed cell proliferation capacity.

Recently, increased frequency of mutations within the MED12 gene was reported in a large cohort of fatal non-anaplastic thyroid cancers (15). This protein is a component of the mediator complex, which functions as transcriptional coactivator in eukaryotic cells by triggering transcriptional initiation through the interaction with both transcription factors and RNA polymerase II (37). Through the advent of high-throughput sequencing technologies MED12 mutations have been reported as frequently occurring in several types of cancer $(38,39)$. Due to its relevant role in controlling gene expression regulation mutations in this gene even if not yet characterized are likely to have relevance in both oncogenic and oncosuppressive pathways. Different from the previous study (15), we did not find a significant association of MED12 mutations and HA-TCs. This discrepancy is likely determined by case selection. Our cohort was limited to ATCs and differentiated PTCs that develop metastatic behavior. By contrast the previous study included in the analysis also poorly differentiated and other histotype of fatal thyroid cancer that were not included in this analysis. Indeed, as previously reported by TCGA for PTCs and genomic profile of ATCs studies, MED12 mutations are uncommon event in both PTCs and ATCs $(10,11)$. Our analysis cannot be considered exhaustive, and it is likely that other genetic events may overlap between ATCs and metastatic PTCs accounting for their aggressiveness. In this regard, we recently reported that duplication of chromosome $1 \mathrm{q}$ is strongly associated with the development of distant metastasis and reduced survival probability in well-differentiated PTCs (14). As well amplification of chromosome 1q has been significantly linked to poorly differentiated thyroid cancers and ATCs and has been correlated with fatal outcome of these tumors, suggesting that unbalanced copy number in this region may confer to thyroid cancer metastasis promoting features $(11,40)$.

In conclusion, this study explored the genetic asset of ATCs and widely metastatic well-differentiated PTCs showing that beside TERT promoter mutations these highly aggressive forms of thyroid cancer have poor genetic commonalities. Our study further highlights the relevance of TERT promoter mutations in driving aggressiveness of thyroid cancer demonstrating the centrality of these alterations for both ATC and DM-PTCs. Even if not conclusive this study provides a new piece of information in the definition of aggressiveness evolution of thyroid cancer lesions.

\section{Supplementary data}

This is linked to the online version of the paper at https://doi.org/10.1530/ EC-18-0386. https://ec.bioscientifica.com https://doi.org/10.1530/EC-18-0386 (c) 2018 The authors Published by Bioscientifica Ltd
This work is licensed under a Creative Commons Attribution-NonCommercial-NoDerivatives 4.0 International License. 


\section{Declaration of interest}

The authors declare that there is no conflict of interest that could be perceived as prejudicing the impartiality of the research reported.

\section{Funding}

This work was supported by the Italian Ministry of Health, GR-201102350937.

\section{References}

1 Davies L \& Welch HG. Current thyroid cancer trends in the United States. JAMA Otolaryngology: Head and Neck Surgery 2014140 317-322. (https://doi.org/10.1001/jamaoto.2014.1)

2 Kondo T, Ezzat S \& Asa SL. Pathogenetic mechanisms in thyroid follicular-cell neoplasia. Nature Reviews Cancer 20066 292-306. (https://doi.org/10.1038/nrc1836)

3 Ragazzi M, Ciarrocchi A, Sancisi V, Gandolfi G, Bisagni A \& Piana S. Update on anaplastic thyroid carcinoma: morphological, molecular, and genetic features of the most aggressive thyroid cancer. International Journal of Endocrinology 20142014 790834. (https://doi. org/10.1155/2014/790834)

4 Gandolfi G, Sancisi V, Piana S \& Ciarrocchi A. Time to re-consider the meaning of BRAF V600E mutation in papillary thyroid carcinoma. International Journal of Cancer 2015137 1001-1011. (https://doi. org/10.1002/ijc.28976)

5 Handkiewicz-Junak D, Czarniecka A \& Jarzab B. Molecular prognostic markers in papillary and follicular thyroid cancer: current status and future directions. Molecular and Cellular Endocrinology 2010322 8-28. (https://doi.org/10.1016/j.mce.2010.01.007)

6 Cappola AR \& Mandel SJ. Molecular testing in thyroid cancer: BRAF mutation status and mortality. JAMA 2013309 1529-1530. (https:// doi.org/10.1001/jama.2013.3620)

7 Cabanillas ME, McFadden DG \& Durante C. Thyroid cancer. Lancet 2016388 2783-2795. (https://doi.org/10.1016/S01406736(16)30172-6)

8 Oishi N, Kondo T, Ebina A, Sato Y, Akaishi J, Hino R, Yamamoto N, Mochizuki K, Nakazawa T, Yokomichi H, et al. Molecular alterations of coexisting thyroid papillary carcinoma and anaplastic carcinoma: identification of TERT mutation as an independent risk factor for transformation. Modern Pathology 201730 1527-1537. (https://doi. org/10.1038/modpathol.2017.75)

9 Quiros RM, Ding HG, Gattuso P, Prinz RA \& Xu X. Evidence that one subset of anaplastic thyroid carcinomas are derived from papillary carcinomas due to BRAF and p53 mutations. Cancer 2005103 2261-2268. (https://doi.org/10.1002/cncr.21073)

10 Cancer Genome Atlas Research Network. Integrated genomic characterization of papillary thyroid carcinoma. Cell 2014159 676-690. (https://doi.org/10.1016/j.cell.2014.09.050)

11 Landa I, Ibrahimpasic T, Boucai L, Sinha R, Knauf JA, Shah RH, Dogan S, Ricarte-Filho JC, Krishnamoorthy GP, Xu B, et al. Genomic and transcriptomic hallmarks of poorly differentiated and anaplastic thyroid cancers. Journal of Clinical Investigation 2016126 1052-1066. (https://doi.org/10.1172/JCI85271)

12 Melo M, da Rocha AG, Batista R, Vinagre J, Martins MJ, Costa G, Ribeiro C, Carrilho F, Leite V, Lobo C, et al. TERT, BRAF, and NRAS in primary thyroid cancer and metastatic disease. Journal of Clinical Endocrinology and Metabolism 2017102 1898-1907. (https://doi. org/10.1210/jc.2016-2785)

13 Pozdeyev N, Gay LM, Sokol ES, Hartmaier R, Deaver KE, Davis S, French JD, Borre PV, LaBarbera DV, Tan AC, et al. Genetic Analysis of 779 Advanced Differentiated and Anaplastic Thyroid Cancers. Clinical Cancer Research 201824 3059-3068. (https://doi. org/10.1158/1078-0432.CCR-18-0373)
14 Gandolfi G, Ragazzi M, de Biase D, Visani M, Zanetti E, Torricelli F, Sancisi V, Gugnoni M, Manzotti G, Braglia L, et al. Genome-wide profiling identifies the THYT1 signature as a distinctive feature of widely metastatic Papillary Thyroid Carcinomas. Oncotarget 20189 1813-1825. (https://doi.org/10.18632/oncotarget.22805)

15 Ibrahimpasic T, Xu B, Landa I, Dogan S, Middha S, Seshan V, Deraje S, Carlson DL, Migliacci J, Knauf JA, et al. Genomic alterations in fatal forms of non-anaplastic thyroid cancer: identification of MED12 and RBM10 as novel thyroid cancer genes associated with tumor virulence. Clinical Cancer Research 201723 5970-5980. (https://doi.org/10.1158/1078-0432.CCR-17-1183)

16 Jang EK, Song DE, Sim SY, Kwon H, Choi YM, Jeon MJ, Han JM, Kim WG, Kim TY, Shong YK, et al. NRAS Codon 61 mutation is associated with distant metastasis in patients with follicular thyroid carcinoma. Thyroid 201424 1275-1281. (https://doi.org/10.1089/ thy.2014.0053)

17 Gandolfi G, Ragazzi M, Frasoldati A, Piana S, Ciarrocchi A \& Sancisi V. TERT promoter mutations are associated with distant metastases in papillary thyroid carcinoma. European Journal of Endocrinology 2015 172 403-413. (https://doi.org/10.1530/EJE-14-0837)

18 Sancisi V, Nicoli D, Ragazzi M, Piana S \& Ciarrocchi A. BRAFV600E mutation does not mean distant metastasis in thyroid papillary carcinomas. Journal of Clinical Endocrinology and Metabolism 201297 E1745-E1749. (https://doi.org/10.1210/jc.2012-1526)

19 de Biase D, Gandolfi G, Ragazzi M, Eszlinger M, Sancisi V, Gugnoni M, Visani M, Pession A, Casadei G, Durante C, et al. TERT promoter mutations in papillary thyroid microcarcinomas. Thyroid 201525 1013-1019. (https://doi.org/10.1089/thy.2015.0101)

20 Landa I, Ganly I, Chan TA, Mitsutake N, Matsuse M, Ibrahimpasic T, Ghossein RA \& Fagin JA. Frequent somatic TERT promoter mutations in thyroid cancer: higher prevalence in advanced forms of the disease. Journal of Clinical Endocrinology and Metabolism 201398 E1562-E1566. (https://doi.org/10.1210/jc.2013-2383)

21 Liu T, Wang N, Cao J, Sofiadis A, Dinets A, Zedenius J, Larsson C $\& \mathrm{Xu}$ D. The age- and shorter telomere-dependent TERT promoter mutation in follicular thyroid cell-derived carcinomas. Oncogene 2014 33 4978-4984. (https://doi.org/10.1038/onc.2013.446)

22 Liu X, Bishop J, Shan Y, Pai S, Liu D, Murugan AK, Sun H, El-Naggar AK \& Xing M. Highly prevalent TERT promoter mutations in aggressive thyroid cancers. Endocrine-Related Cancer 201320 603-610. (https://doi.org/10.1530/ERC-13-0210)

23 Melo M, da Rocha AG, Vinagre J, Batista R, Peixoto J, Tavares C, Celestino R, Almeida A, Salgado C, Eloy C, et al. TERT promoter mutations are a major indicator of poor outcome in differentiated thyroid carcinomas. Journal of Clinical Endocrinology and Metabolism 201499 E754-E765. (https://doi.org/10.1210/jc.2013-3734)

24 Vinagre J, Almeida A, Populo H, Batista R, Lyra J, Pinto V, Coelho R, Celestino R, Prazeres H, Lima L, et al. Frequency of TERT promoter mutations in human cancers. Nature Communications 201342185. (https://doi.org/10.1038/ncomms3185)

25 Hanahan D \& Weinberg RA. Hallmarks of cancer: the next generation. Cell 2011144 646-674. (https://doi.org/10.1016/j. cell.2011.02.013)

26 Collins K. The biogenesis and regulation of telomerase holoenzymes. Nature Reviews Molecular Cell Biology 20067 484-494. (https://doi. org/10.1038/nrm1961)

27 Greider CW \& Blackburn EH. Identification of a specific telomere terminal transferase activity in Tetrahymena extracts. Cell 198543 405-413. (https://doi.org/10.1016/0092-8674(85)90170-9)

28 Horn S, Figl A, Rachakonda PS, Fischer C, Sucker A, Gast A, Kadel S, Moll I, Nagore E, Hemminki K, et al. TERT promoter mutations in familial and sporadic melanoma. Science 2013339 959-961. (https:// doi.org/10.1126/science.1230062)

29 Huang FW, Hodis E, Xu MJ, Kryukov GV, Chin L \& Garraway LA. Highly recurrent TERT promoter mutations in human melanoma. Science 2013339 957-959. (https://doi.org/10.1126/science.1229259)

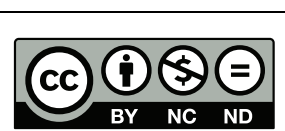

This work is licensed under a Creative Commons Attribution-NonCommercial-NoDerivatives 4.0 International License. 
30 Killela PJ, Reitman ZJ, Jiao Y, Bettegowda C, Agrawal N, Diaz LA Jr, Friedman AH, Friedman H, Gallia GL, Giovanella BC, et al. TERT promoter mutations occur frequently in gliomas and a subset of tumors derived from cells with low rates of self-renewal. PNAS 2013 110 6021-6026. (https://doi.org/10.1073/pnas.1303607110)

31 Arita H, Narita Y, Fukushima S, Tateishi K, Matsushita Y, Yoshida A, Miyakita Y, Ohno M, Collins VP, Kawahara N, et al. Upregulating mutations in the TERT promoter commonly occur in adult malignant gliomas and are strongly associated with total 1p19q loss. Acta Neuropathologica 2013126 267-276. (https://doi.org/10.1007/ s00401-013-1141-6)

32 Nault JC, Mallet M, Pilati C, Calderaro J, Bioulac-Sage P, Laurent C, Laurent A, Cherqui D, Balabaud C \& Zucman-Rossi J. High frequency of telomerase reverse-transcriptase promoter somatic mutations in hepatocellular carcinoma and preneoplastic lesions. Nature Communications 20134 2218. (https://doi.org/10.1038/ncomms3218)

33 Rachakonda PS, Hosen I, de Verdier PJ, Fallah M, Heidenreich B, Ryk C, Wiklund NP, Steineck G, Schadendorf D, Hemminki K, et al. TERT promoter mutations in bladder cancer affect patient survival and disease recurrence through modification by a common polymorphism. PNAS 2013110 17426-17431. (https://doi. org/10.1073/pnas.1310522110)

34 Tallet A, Nault JC, Renier A, Hysi I, Galateau-Salle F, Cazes A Copin MC, Hofman P, Andujar P, Le Pimpec-Barthes F, et al. Overexpression and promoter mutation of the TERT gene in malignant pleural mesothelioma. Oncogene 201433 3748-3752. (https://doi.org/10.1038/onc.2013.351)
35 Song YS, Lim JA, Choi H, Won JK, Moon JH, Cho SW, Lee KE, Park YJ, Yi KH, Park DJ, et al. Prognostic effects of TERT promoter mutations are enhanced by coexistence with BRAF or RAS mutations and strengthen the risk prediction by the ATA or TNM staging system in differentiated thyroid cancer patients. Cancer 2016122 1370-1379. (https://doi.org/10.1002/cncr.29934)

36 Saretzki G, Sitte N, Merkel U, Wurm RE \& von Zglinicki T. Telomere shortening triggers a p53-dependent cell cycle arrest via accumulation of G-rich single stranded DNA fragments. Oncogene 199918 5148-5158. (https://doi.org/10.1038/sj.onc.1202898)

37 Flanagan PM, Kelleher RJ, 3rd, Sayre MH, Tschochner H \& Kornberg RD. A mediator required for activation of RNA polymerase II transcription in vitro. Nature 1991350 436-438. (https://doi. org/10.1038/350436a0)

38 Lawrence MS, Stojanov P, Mermel CH, Robinson JT, Garraway LA, Golub TR, Meyerson M, Gabriel SB, Lander ES \& Getz G. Discovery and saturation analysis of cancer genes across 21 tumour types. Nature $2014 \mathbf{5 0 5}$ 495-501. (https://doi.org/ $10.1038 /$ nature12912)

39 Vogelstein B, Papadopoulos N, Velculescu VE, Zhou S, Diaz LA Jr \& Kinzler KW. Cancer genome landscapes. Science 2013339 1546-1558. (https://doi.org/10.1126/science.1235122)

40 Wreesmann VB, Sieczka EM, Socci ND, Hezel M, Belbin TJ, Childs G, Patel SG, Patel KN, Tallini G, Prystowsky M, et al. Genomewide profiling of papillary thyroid cancer identifies MUC1 as an independent prognostic marker. Cancer Research 200464 3780-3789. (https://doi.org/10.1158/0008-5472.CAN-03-1460)

Received in final form 24 October 2018

Accepted 30 October 2018

Accepted Preprint published online 1 November 2018 https://ec.bioscientifica.com https://doi.org/10.1530/EC-18-0386 (c) 2018 The authors Published by Bioscientifica Ltd

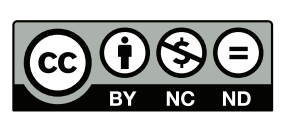

This work is licensed under a Creative Commons Attribution-NonCommercial-NoDerivatives 4.0 International License. 